Bentham open
CrossMark
Content list available at: www.benthamopen.com/TOCIEJ/
DOI: $10.2174 / 1874149501610010093$

\title{
Congestion Risk Evaluation and Precaution of Passenger Flow in Metro Stations
}

\author{
Kai $\mathrm{Lu}^{1}$ and Baoming $\operatorname{Han}^{1,2, *}$ \\ ${ }^{1}$ School of Traffic and Transportation, Beijing Jiaotong University, Beijing 100044, P.R. China \\ ${ }^{2}$ MOE Key Laboratory of Rail Traffic Control and Safety, Beijing Jiaotong University, Beijing 100044, P.R. China
}

\begin{abstract}
Given the security problems of the urban rail transportation, this paper proposes a methodology for congestion risk evaluation and precaution in order to guarantee the safety of passengers and improve the operation efficiency in metro stations. To begin with, we selected the retention rate of the platform, the waiting rate of the ticket gate and the transfer efficiency as the indexes for the station congestion precaution system and created models to calculate the threshold respectively. By reasonably combining these three indexes, a congestion warning level function was set up to evaluate the congestion risk and determine the warning level. The characteristics of the proposed model are its quick decision results and ease of handling. With the determined warning level, some strategies are suggested to relieve the pressure. Finally, a practical application in Beijing's GuoMao metro station was performed to verify the feasibility and practicability of the proposed congestion precaution model.
\end{abstract}

Keywords: Congestion evaluation level function, congestion precaution, metro station, response action, threshold value.

\section{INTRODUCTION}

With the rapid development of the urban rail transportation in Beijing, the volume of passengers has reached ten million per day. The large amount of passengers leads to many safety problems, some of which are even deadly. The issue of safety is coming to the limelight and has aroused wide attention. In order to guarantee the safety of passengers and improve the efficiency of the metro station, the evaluation for congestion risk and precaution theory must be and has been applied to the operation and management of urban rail operation.

Congestion risk evaluation and precaution system is similar to an early warning system, which is an information chain consisting of detectors, decisions and breakers to minimize the negative impact on the stability in the physical world. Early warning theory has been successfully used in economics, nature disasters and other fields [1]. Following the early warning model from other fields, the basic procedure of congestion evaluation and precaution has been established [2] as shown in (Fig. 1).

\subsection{Passenger Data Monitoring and Forecasting}

The equipment, such as cameras, gates and infrared devices, can be used to get the passenger data which can be applied in a specific model for predicting the short-term tendency of the passenger flow and the operation. The predicted data is used for congestion evaluation and precaution. The short-term forecasting has developed quickly for nearly three decades [3]. The basic models can be divided into five types: linear models, nonlinear models, artificial intelligence models, composite models and simulation forecasting models.

\footnotetext{
* Address correspondence to this author at the Beijing Jiaotong University, No.3 Shangyuancun, Haidian District, Beijing, P.R. China 100044; Tel: 86-10-51684197; E-mails: lukai_bjtu@163.com, srail_bjtu@bjtu.edu.cn
} 


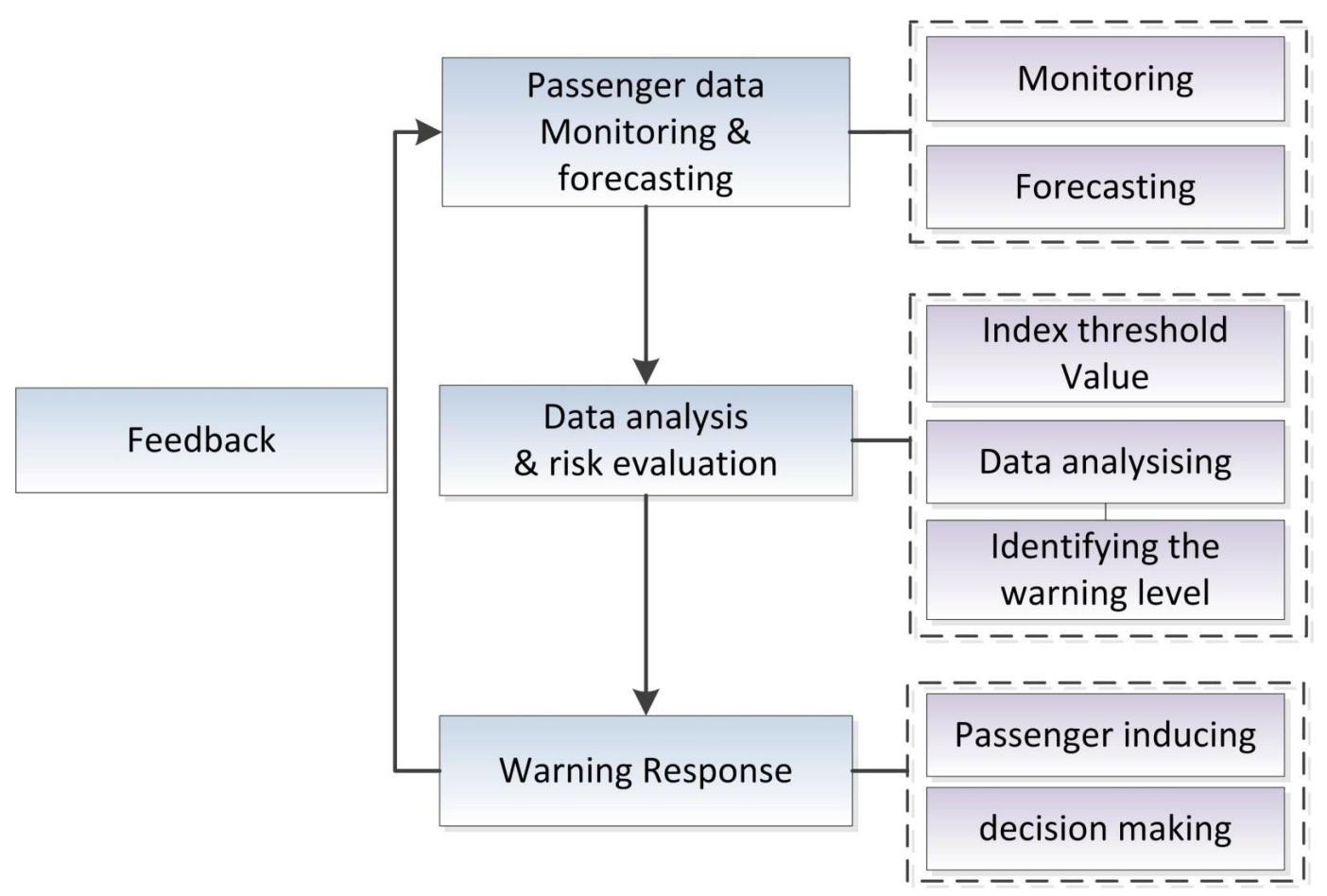

Fig. (1). The procedure of congestion evaluation and precaution in metro station.

There are four basic kinds of linear models: time series model, Kalman filtering model, exponential smoothing model, and adaptive model. The first one focuses on time based rules and can be applied to short or long period forecast [4]. The second one mainly optimizes the indexes, when it comes to forecasting [5]. The third one depends more on newly updated data, and the last one can reflect the differences between the different emergency accidents and changing weights of other factors [6].

As for nonlinear models, they mainly depend on the wavelet analysis, which focuses on the Origin-Destination forecasting and total volume of the station [7], catastrophe theory, which takes the urban railway system as a mutable system, and chaos theory, which utilizing the technology of phase-space reconstruction, empirically studies the short term forecast [8].

The artificial intelligence model is widely believed to need a set of study examples, usually the historical data and the model, whereby it can study the connections between the input and the output independently. The most famous artificial intelligence system is the neural network model. The nonparametric models and support vector models also belong to this classification [9 - 12].

Composite modeling has been used in order to overcome the limits of the different methods discussed above. Some researchers combine different models, such as EMD-BPN [13, 14], to forecast the volume of the passengers. As for the last one, with the help of the cellular automaton model, the volume can be forecasted.

\subsection{Congestion Index and Risk Evaluation}

The congestion estimation system for metro station compares the input data with the threshold value to evaluate the current condition and decides if it is necessary to announce a warning.

To establish the threshold value, the Code for the Design of Metro (GB 50157-2003) and Urban Rail Transit Operation Guide give out several service levels for equipment, such as stairs and lifts. The basic capacity levels of the fare gates, transfer channels and the stairs in the station are also set. Additionally, some local rules are published for specific cities, such as Beijing's Urban Rail Traffic Safety Operations Management Measures, to guarantee the security of the operation.

Sometimes the service efficiency depends on the density and the velocity of the passengers. Different researchers used different diagrams to plot the relationship of passenger density and velocity, such as linear, log function and triangle [15]. Based on the transportation dynamic theory, Lu [16] found that passenger moving velocities depend on 
the friction and the passengers around them. The back- front friction is log to the density and the left-right friction is influenced by the density, and the relationship is linear.

Some preliminary researchers established the threshold values for density and velocity. The basic density for movement is $0.92 \mathrm{~m}^{2} / \mathrm{m}^{2}$ and the maximal moving velocity is 1.14 person $/ m \times s$ [17]. Some researchers studied moving passengers in a channel. The velocity is related to the density of passengers, and when the density approaches 4 person $/ \mathrm{m}^{2}$, congestion might happen [18].

The pre-research indexes mostly focus on the passenger density or velocity in the station, however, the velocity and density differs a lot in different parts of the station. Meanwhile, the velocity and the density are hard to obtain in the station. For these, this study selected three different indexes to evaluate the congestion in the station.

\subsection{Congestion Precaution and Warning Response}

When the congestion condition reaches to the warning level, the manager must take some actions to ensure normal operations, which is called warning response or risk management. Preliminary studies discuss different methods for handling risks such as marshaling modes, adjusting time table and optimizing the organization in the station. With sudden large numbers of passengers, different vehicle loops can be chosen for transferring the passengers [19]. In the station, the passengers' paths or the marketing plans need to be adjusted based on the changes in the number of passengers [20].

Finally, the system collects the data again and checks the results of the precaution and responsive actions.

Even though the specific theories and methods, discussed above, have developed rapidly. The literatures seldom discussed the congestion precaution procedure. This study mainly illustrated the whole procedure of congestion precaution in the urban rail station. The indicators for the congestion precaution and the threshold values were established by actual surveys of successive walking paths in a transfer station. In order to determine the congestion warning level more quickly, this study put forward a congestion evaluation function and some related suggestions based on the warning level to prevent greater damage. All of these theories were applied in Beijing GuoMao station (Section 4) to illustrate the practicability and validity.

\section{THE INDEX OF CONGESTION PRECAUTION}

The urban rail system is a complex system and contains much equipment, which influences each other. The selected data indexes should be systematic, coincident with each other. Everyone can reflect an aspect of the station and still has no overlap at the same time. Second, the index data should be easily collected, analyzed, and suitable for the short-term forecasting. Finally, the threshold of the index should reflect the practical situation, not only copy the standard from other counties.

According to the passenger paths in the station, we select stranded passengers i.e. those needing to wait for the next train on the platform, waiting rate at the ticket gates, and the efficiency of the transfer channel as the indexes for the metro transfer station. The warning standards are different according to time periods and cities. This study focuses on the peak hour and the thresholds can be used for most of the transfer stations in Beijing, which can also be applied in off-peak period.

\subsection{Retention Rate of the Platform}

In this study, we assume that the arrival and departure of the trains is a quick movement, which can finish immediately. The behavior of the passengers on the platform is periodic which corresponds with the departure and arrival of the trains. When the $(j-1)^{\text {th }}$ train departs from the station, generally, passengers on platform will board on the $(j-1)^{t h}$ train. The number of waiting passenger on the platform gets to the minimum. When the train departs from the station, the waiting passengers on the platform will increase and get to the maximum when the $j^{\text {th }}$ train arriving on the platform. When the $j^{\text {th }}$ train departs from the platform, the passengers on the platform will reach to the minimum again. The passenger period can be plotted as shown in (Fig. 2). 


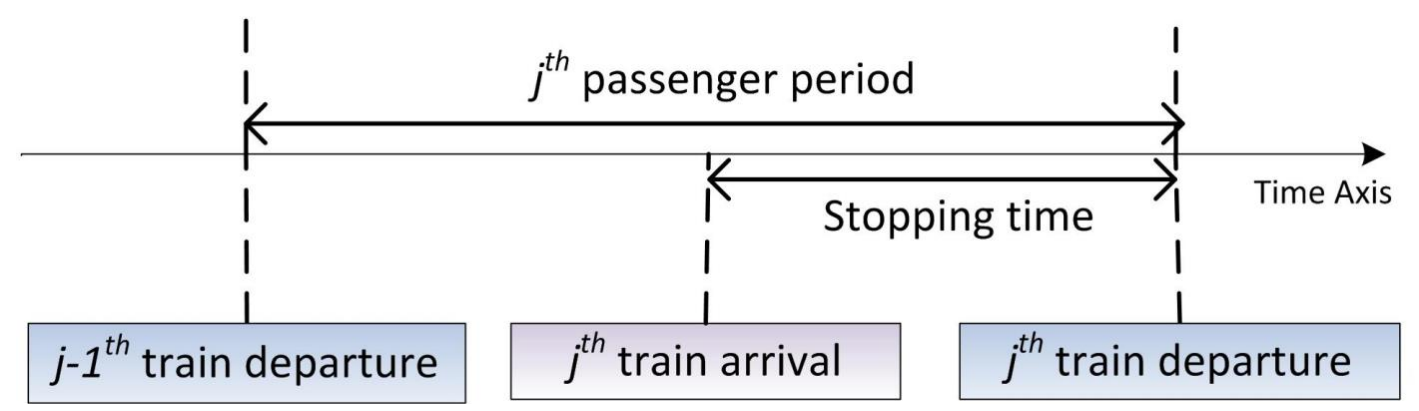

Fig. (2). The passenger period in the platform.

Retention rate $\eta_{r}$ of the platform is the index to describe the proportion of the stranded passengers $N_{r i}^{j}$ who wait on the platform, but can't get on the current train and need to wait for a second one. $\eta_{r}$ can be calculated by Eq. 1 .

$$
\eta_{r}=\frac{N_{r i}^{j}}{N_{w i}^{j}}
$$

For the $i^{\text {th }}$ platform in $j^{\text {th }}$ passenger period, the number of stranded passengers is restrained by the waiting passengers $N_{w i}^{j}$, and boarding passengers $N_{b i}^{j}$, who can get on the $j^{\text {th }}$ train during $j^{\text {th }}$ passenger period. For every shielded gate, the stranded passengers can be calculated by Eq. 2 , where $[\cdot]$ is the rounding function.

$$
N_{r i}^{j}=\left[\max \left\{N_{w i}^{j}-N_{b i}^{j}, 0\right\}\right]
$$

The waiting passengers $N_{w i}^{j}$ on the platform can be calculated by Eq. 3 .

$$
N_{w i}^{j}=N_{r i}^{j-1}+N_{i i}^{j}+N_{t i}^{j}
$$

Where $N_{b i}^{j-1}$ is the stranded passengers in last period, $N_{i i}^{j}$ is the passengers who checking-in in $j^{t h}$ period and $N_{t i}^{j}$ is the transfer passengers who will transfer to this line in this station.

Boarding passenger $N_{b i}^{j}$, depending on the loading rate $\beta_{i}^{j}$ and the train fixed passenger number $C_{\mathrm{O}}$, can be calculated by Eq. 4 .

$$
N_{b i}^{j}=\beta_{i}^{j} C_{0}
$$

The waiting area is limited. The maximal number of waiting passengers $N_{w i}$ can be calculated by Eq. 5 .

$$
N_{w i 0}=\alpha \frac{s_{w i}}{n_{0}}
$$

Where $S_{w i}$ is the available area in the platform for the passengers waiting for the train, $n$ is the basic space for the passengers to stand and $\alpha$ is reduction factor due to the different gender of the passengers and the belongings. When the average volume of the waiting passengers reaches its maximum, the congestion precaution system should be activated.

Table 1. The congestion warning level of the retention rate of the platform.

\begin{tabular}{|c|c|c|}
\hline $\begin{array}{c}\text { Warning } \\
\text { Level }\end{array}$ & Warning Standard & Description \\
\hline $\mathrm{d}$ & $N_{w i}^{j}>N_{w i, \eta_{r}}=0$ & $\begin{array}{r}\text { The waiting passengers on the platform exceed hthe maximum number of waiting passengers on the platform, } \\
\text { but all the waiting passengers can board on the train with no stranded passengers }\end{array}$ \\
\hline $\mathrm{c}$ & $\eta_{r \in(0 \%, 15 \%]}$ & A few passengers stranded on the platform waiting for the next train \\
\hline $\mathrm{b}$ & $\eta_{r \in(15 \%, 40 \%]}$ & Some passengers need to wait for the next train \\
\hline $\mathrm{a}$ & $\eta_{r}>40 \%$ & Most of the passengers are left on the platform and the platform is extremely crowded \\
\hline
\end{tabular}

\subsection{Waiting Rate of the Ticket Gates}

Ticket gates play a crucial role in the station and can count the number of the checking-in passengers. The efficiency of the ticket gate influences the volume of the passengers and the condition of the station. Sometimes at the 
peak-hours, because of the large amount of incoming passengers, many of them need to wait in a queue behind the ticket gates. The service time of the ticket gates obeys the negative distribution; the passenger arriving rule is subjected to the Poisson distribution [21]. Ticket gates serving model can be described as $M / M / C / \infty / \infty$ model in queuingbased models. The waiting queue $L_{q}$ (unit: person) can be calculated by Eq. 6 .

$$
\begin{aligned}
& L_{q}=\frac{(c \rho)^{c} \cdot \rho}{c !(1-\rho)^{2}} \cdot P_{0} \\
& P_{0}=\left[\sum_{k=0}^{c-1} \frac{1}{k !}\left(\frac{\lambda}{\mu}\right)^{k}+\frac{1}{c !} \cdot \frac{1}{1-\rho} \cdot\left(\frac{\lambda}{\mu}\right)^{c}\right]^{-1}, \rho=\frac{\lambda}{c \mu}<1
\end{aligned}
$$

Where $c$ is the number of the ticket gates, $\lambda$ is the average service frequency, $\mu$ is the average number of checking-in passengers. Both $\lambda$ and $\mu$ can be captured by historical data and simulation. Waiting rate $\eta_{w}$, is variable to describe the waiting rate of the passengers and can be calculated by Eq. 7 .

$$
\eta_{w}=\frac{L_{w}}{L_{q}}
$$

Where $L_{w}$ (unit: person) is the actual number of waiting passengers behind the ticket gate and $L_{a}$ are the queuing passengers.

After thirteen surveys and gathering research data from the ticket gates in Beijing Metro stations, such as Dong Dan,

\begin{tabular}{|c|c|c|}
\hline Warning Level & Warning Standard & Description \\
\hline $\mathrm{D}$ & Get to the maximal efficiency $\mathrm{L}_{\mathrm{w}}=0$ & $\begin{array}{c}\text { Passengers passing the ticket gates constantly and the close-open frequency of the ticket gate is } \\
\text { high }\end{array}$ \\
\hline $\mathrm{C}$ & $\eta_{\mathrm{w}} \in(0 \%, 40 \%]$ & A few passengers waiting in line and the condition is in order \\
\hline B & $\eta_{\mathrm{w}} \in(40 \%, 70 \%]$ & $\begin{array}{l}\text { A lot of passengers wait in a queue and some passengers need to step back and repeat checking } \\
\text { in }\end{array}$ \\
\hline A & $\eta_{\mathrm{w}}>70 \%$ & The ticket gates can't close and sometimes break down \\
\hline
\end{tabular}
$\mathrm{Xi}$ Zhimen, this study divides the service into four levels, as shown in (Table 2).

Table 2. The congestion warning level of the waiting rate for the ticket gate.

\subsection{Transfer Efficiency}

For transfer stations, the transfer efficiency rating is a very important index to estimate the condition of the station. The transfer efficiency depends on the transfer distance and transfer time. The walking velocity varies with different equipment such as the stairs and escalators in the channel. The transfer time $T_{t}$ (unit: second) can be calculated as Eq. 8 .

$$
T_{t}=\sum_{k=1}^{n} \frac{d_{k}}{v_{k}}
$$

Where $n$ is the number of equipment such as stairs and elevators in the transfer channel, $d_{k}$ is the distance between different equipment and $v_{k}$ is the walking velocity between equipment. Putting the theoretical velocity $v_{k}$ in Eq. 8 , the result is the theoretical transfer time $T_{t}$ (unit: second). The transfer efficiency $\eta_{t}$ can be calculated by Eq. 9 .

$$
\eta_{t}=\frac{T_{t}}{T_{t 0}}
$$

When $\eta_{t} \geq 1$, there can be a little bit of congestion in the transfer channel. The warning levels for the different efficiencies are shown as in (Table 3 ).

Table 3. The congestion warning level of the Transfer efficiency.

\begin{tabular}{|c|c|c|}
\hline $\begin{array}{c}\text { Warning } \\
\text { Level }\end{array}$ & Warning Standard & Description \\
\hline 4 & $\eta_{t} \in(1,1.3]$ & $\begin{array}{c}\text { The efficiency of the channel up to its limitation. There are no passengers waiting before the lift, passengers } \\
\text { can move freely }\end{array}$ \\
\hline 3 & $\eta_{t} \in(1.3,1.7]$ & Some queues appear before the lift and the stairs, but everything is under control \\
\hline
\end{tabular}


(Table $\square$ ) contd.....

\begin{tabular}{|c|c|c|}
\hline $\begin{array}{c}\text { Warning } \\
\text { Level }\end{array}$ & Warning Standard & Description \\
\hline 2 & $\eta_{w \in}(1.7,2]$ & Some other part in the channel develop waiting lines, passenger path in the channel is fixed \\
\hline 1 & $\eta_{t} \geq 2$ & The velocity of the passengers is slow, mostly cannot move in a horizontal direction \\
\hline
\end{tabular}

\section{CONGESTION EVALUATION FOR A SUBWAY STATION}

\subsection{Congestion Evaluation Level Standards}

When dividing the metro congestion warning system into many levels, the warning level will fluctuate between levels. If the number of the warning levels is just one or two, each level may cover too large a range, thereby leading to an incorrect warning level and incorrect response for the actual situation. Due to the seriousness, the warning system is divided into four levels with different colors for quick reference. The standards and colors are listed in the (Table 4).

Table 4. Congestion evaluation levels for a subway station.

\begin{tabular}{|c|c|c|}
\hline Level & Color & Warning standard \\
\hline IV & Blue & $\begin{array}{l}\text { The station is a little bit crowded, passengers can move freely, some parts of the station have a little congestion, but there are no } \\
\text { passengers stranded on the platform. }\end{array}$ \\
\hline III & Yellow & $\begin{array}{l}\text { There is some congestion in the station and will last for one train departure interval. A few passengers are stranded on the platform. } \\
\text { With some organization, the crowd's situation can be significantly eased. }\end{array}$ \\
\hline II & Orange & $\begin{array}{c}\text { All the facilities are in full load condition. The waiting time is longer than a departure interval. Some passengers are stranded on the } \\
\text { platform. Passengers must wait in lines. }\end{array}$ \\
\hline I & Red & $\begin{array}{l}\text { The station is overwhelmingly crowded and the density is exceedingly high. There are many hidden dangers and risks to passenger } \\
\text { safety. The transfer efficiency is very low. Most of the passengers are waiting or delayed. }\end{array}$ \\
\hline
\end{tabular}

\subsection{Congestion Evaluation Level Function}

This study selected the waiting rate at the ticket gate, the retention rate at the platform and transfer efficiency as the parameters to measure for the congestion level of the station. What's more, this article puts forward a method, where congestion evaluation function combines these three parameters.

Taking the blue level into consideration, the congestion evaluation function is divided into four levels.

\section{(i) 3-Dimensional Congestion Precaution Function}

Waiting rate level, transfer channel level and platform retention rate can be set into a 3-Dimensional, rectangular, coordinate system. The input data can identify a specific point in the 3-Dimensional space, which can illustrate the congestion level. The entire situation within the station is drawn in the rectangular coordinate system as shown in (Fig. 3).

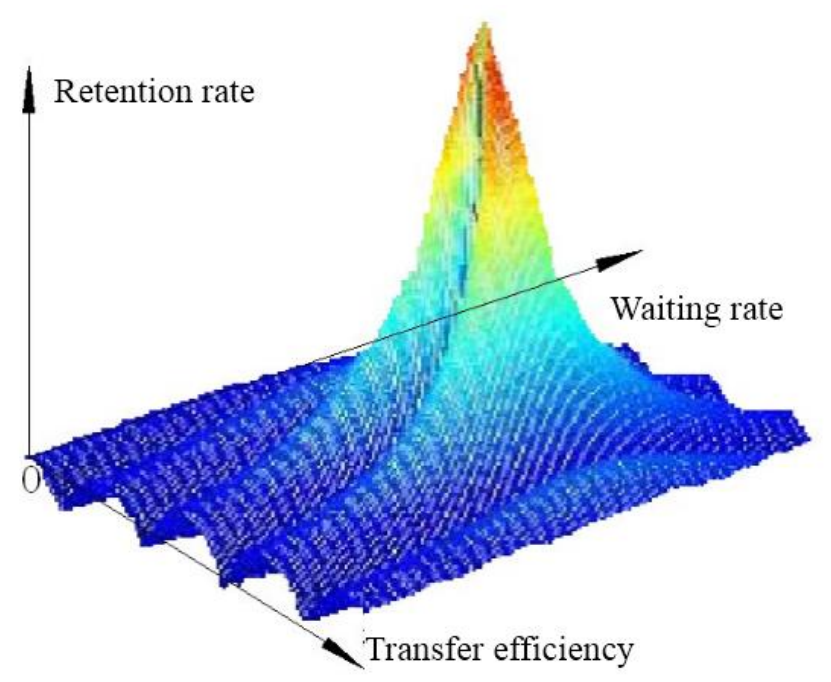

Fig. (3). 3-Dimensional congestion evaluation function. 
This method can indicate the warning situation accurately and comprehensively. However the 3-D surface is hard to estimate, and sometimes it will not be a smooth or constant surface. In order to make it more valid and easier to understand, the 3-D surface is projected into the axial plane xoy, yoz, xoz respectively to simplify the 3-D function.

\section{(ii) 2-Dimensional Congestion Warning Function}

When projecting the surface into the coordinate planes, every plane can reflect two parameters. Take ticket-gate and platform retention as an example. If the platform is crowded but there is no congestion appearing at the ticket gates, when passengers boarding on a train, the passengers on the platform will decrease and will not be as crowded as before. The warning level is blue. However, if the passengers at the ticket gate increased, the platform will become more and more crowded, and there will be more passengers waiting on the platform. When that happens, quite a few measures should be taken such as channelizing or separation. The congestion warning level should be yellow. Similar to the above, the graph of ticket-gate and platform retention can be seen in (Fig. 4).

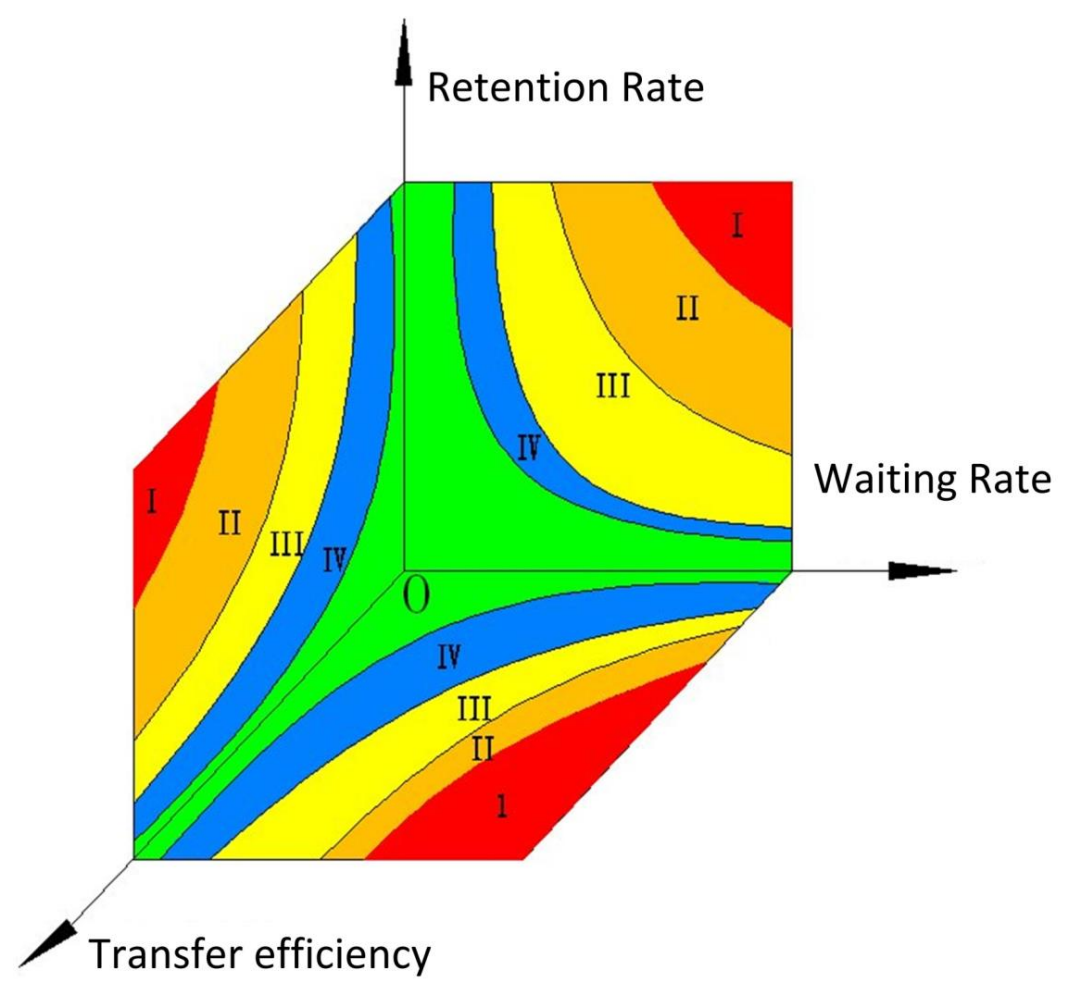

Fig. (4). 2-Dimensional congestion evaluation function.

Since any two indexes can determine a congestion level, one should select the most serious level as the warning level for the station.

This method significantly simplifies the determination period. However, it still has other shortcomings, such as the curve of the two indexes is hard to accurately understand. Additionally, since the number of passengers in the station rapidly changes, the warning level might also change frequently. To solve these visual problems, this study changed the curve graph to a matrix as shown below.

\section{(iii) Matrix Congestion Warning Model}

The determination of congestion warning level becomes simpler via a matrix. According to the twelve times of surveying in GuoMao station, the warning matrix is been established as shown in (Table 5). If the ticket-gates, platform retention and transfer channel warning level are C, 2 and b, respectively. According to the matrix table, The warning level is III, III and II. Choosing the more serious level as the warning level, the warning level of the station is II. 
Table 5. The congestion warning matrix.

\begin{tabular}{|c|c|c|c|c|c|c|c|c|c|}
\hline & & \multicolumn{4}{|c|}{ Transfer efficiency $\eta_{t}$ Warning level } & \multicolumn{4}{|c|}{ Retention rate $\eta_{t}$ Warning level } \\
\hline & & 4 & 3 & 2 & 1 & $\bar{d}$ & $\mathrm{c}$ & $\mathrm{b}$ & $\bar{a}$ \\
\hline \multirow{4}{*}{ Waiting rate $\eta_{w}$ Warning level } & $\mathrm{D}$ & IV & IV & III & III & IV & III & III & II \\
\hline & $\mathrm{C}$ & IV & IV & III & III & IV & III & III & II \\
\hline & $\mathrm{B}$ & IV & III & III & III & IV & III & II & II \\
\hline & A & IV & III & II & II & III & II & I & I \\
\hline \multirow{4}{*}{ Transfer fficiency $\eta_{t}$ Warning level } & 4 & -- & -- & -- & -- & IV & IV & III & II \\
\hline & 3 & -- & -- & -- & -- & IV & III & III & II \\
\hline & 2 & -- & -- & -- & -- & IV & III & II & II \\
\hline & 1 & -- & -- & -- & -- & III & II & I & I \\
\hline
\end{tabular}

In this way, the method can reduce the fluctuations caused by quick changes in passenger numbers in the subway station.

\subsection{Congestion Precaution and Response Action}

Level IV (Blue) At this level the operation of the station is under control. With increasing number of passengers, some equipment should be turned on and switch to the open direction, and change the operation velocity of the equipment, such as the elevators and the ticket-gates.

Level III (Yellow) In this situation, the frequency of the subway trains should be increased and thereby reduce the intervals between trains. Additional staff should be sent to the platforms to improve the boarding and alighting velocity in order to relieve the congestion in the subway platform and reduce the safety risks.

Level II (Orange) Checking-in passengers at the ticket-gates should be limited to reduce the passengers on the platform. Some measures such as channelization can be taken which can reduce the conflict of the passenger-path in the station to increase the velocity. Cooperating with other subway stations to decrease the loading rate of trains is also a good choice.

Level I (Red) At this warning level, quite a few trains need to bypass some stations. The stations need to work with other transportation modes to reduce the number of passengers in the station and meet the demand of the passengers who cannot get on a train.

\section{PRACTICAL APPLICATION}

\subsection{Brief Introduction of GuoMao Station}

GuoMao station is a transfer station between Line 1 and Line 10 of Beijing metro. This station is located in a busy intersection surrounded by a multitude of points of interest, which attract a great flow of passengers. Fig. (5) demonstrates the main body of the station, the blue one is Line 10 and the purple one is Line 1 . The internal passenger flow lines include in-station flow lines, out-station flow lines and transfer flow lines between Line 1 and Line 10.

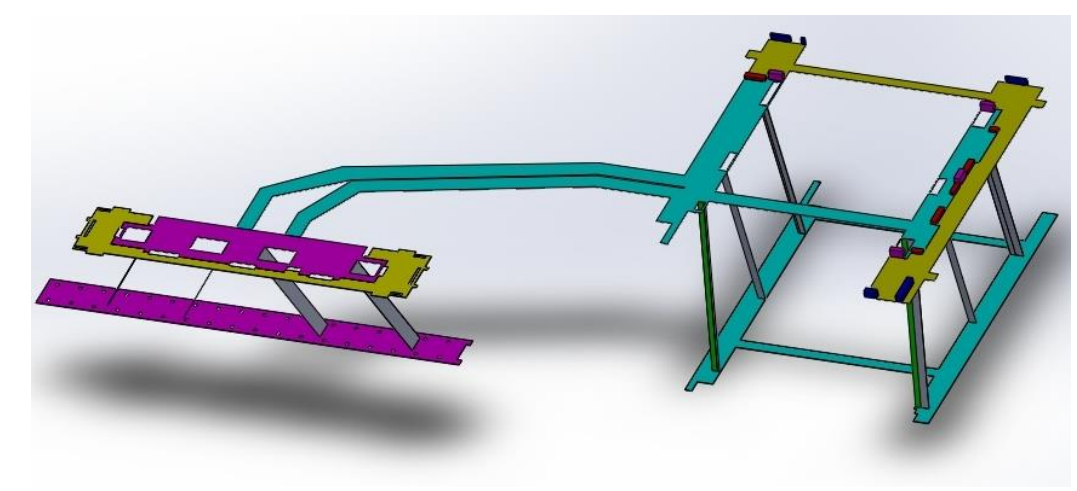

Fig. (5). The main body of GuoMao station. 
During the morning peak-hours, the Line 1 platform is more crowded than the one in Line 10. Most of the passengers transfer from Line 1 to Line 10. This study looks at the weakest positions in the station as examples, with the actual data collected in the station to apply the congestion precaution theory discussed above.

\subsection{Three Indexes of Congestion Precaution in GuoMao Station}

\section{(i) Waiting Rate for the Ticket Gate}

GuoMao station is in the Beijing Central Business District (CBD). In the morning peak-hour, many passengers get out of the station to the workplace. The exiting passengers are much more than checking-in passengers. The capacity of the ticket gate is enough, and therefore turning out the congestion precaution of ticket gate is partly dispensable.

\section{(ii) Retention Rate of the Platform}

During the morning peak-hour, from 7:30 to 8:30, on the Line 1's platform, the checking-in and transfer passengers are collected as shown in Table 6, Column 1. For Line 1, the fixed number of the capacity is 1460. During super peak time, from $7: 45$ to $8: 15$, the loading factor is 1.05 , and 1.02 in rest peak-hour time in the morning. The boarding passenger numbers were calculated from Eq. 4, above. The maximal number of waiting passengers, $N_{w i}$, is 255 . From Eqs. 1-5, and Table 1, the GuoMao retention rate and congestion warning level are calculated in Table 6, below:

Table 6. The congestion warning level of the station Line I platform during morning peak hour.

\begin{tabular}{|c|c|c|c|c|c|c|}
\hline Time & $\begin{array}{c}\text { Checking-in and transfer } \\
\text { passenger/person }\end{array}$ & $\begin{array}{c}\text { Vehicle capacity } \\
\text { /person }\end{array}$ & $\begin{array}{c}\text { Stranded } \\
\text { passengers /person }\end{array}$ & $\begin{array}{c}\text { Waiting passengers/ } \\
\text { person }\end{array}$ & Stranded ratio & $\begin{array}{c}\text { Congestion } \\
\text { warning level }\end{array}$ \\
\hline $7: 31: 30$ & 224 & 263 & 0 & 224 & $0.00 \%$ & -- \\
\hline 7:33:30 & 189 & 263 & 0 & 189 & $0.00 \%$ & -- \\
\hline $7: 35: 30$ & 226 & 263 & 0 & 226 & $0.00 \%$ & d \\
\hline $7: 37: 30$ & 227 & 263 & 0 & 227 & $0.00 \%$ & d \\
\hline 7:39:30 & 220 & 263 & 0 & 220 & $0.00 \%$ & -- \\
\hline $7: 41: 30$ & 245 & 219 & 26 & 245 & $10.72 \%$ & $\mathrm{c}$ \\
\hline 7:43:30 & 255 & 219 & 36 & 282 & $12.86 \%$ & $\mathrm{c}$ \\
\hline $7: 45: 30$ & 239 & 219 & 20 & 275 & $7.35 \%$ & $\mathrm{c}$ \\
\hline 7:47:30 & 218 & 219 & 0 & 238 & $0.00 \%$ & $\mathrm{~d}$ \\
\hline 7:49:30 & 271 & 219 & 52 & 271 & $19.07 \%$ & $\mathrm{~b}$ \\
\hline 7:51:30 & 240 & 219 & 21 & 292 & $7.31 \%$ & $\mathrm{c}$ \\
\hline $7: 53: 30$ & 251 & 219 & 32 & 272 & $11.68 \%$ & $\mathrm{c}$ \\
\hline 7:55:30 & 248 & 219 & 29 & 279 & $10.20 \%$ & $\mathrm{c}$ \\
\hline $7: 57: 30$ & 259 & 219 & 40 & 288 & $13.93 \%$ & $\mathrm{c}$ \\
\hline 7:59:30 & 284 & 219 & 65 & 324 & $20.07 \%$ & $\mathrm{~b}$ \\
\hline $8: 01: 30$ & 260 & 219 & 41 & 325 & $12.66 \%$ & $\mathrm{c}$ \\
\hline 8:03:30 & 261 & 219 & 42 & 302 & $13.97 \%$ & $\mathrm{c}$ \\
\hline $8: 05: 30$ & 252 & 219 & 33 & 294 & $11.18 \%$ & $\mathrm{c}$ \\
\hline $8: 07: 30$ & 271 & 219 & 52 & 304 & $17.00 \%$ & $\mathrm{~b}$ \\
\hline 8:09:30 & 276 & 219 & 57 & 328 & $17.42 \%$ & $\mathrm{~b}$ \\
\hline $8: 11: 30$ & 210 & 219 & 0 & 267 & $0.00 \%$ & $\mathrm{~d}$ \\
\hline 8:13:30 & 268 & 219 & 49 & 268 & $18.29 \%$ & $\mathrm{~b}$ \\
\hline $8: 15: 30$ & 271 & 219 & 52 & 320 & $16.29 \%$ & $\mathrm{~b}$ \\
\hline $8: 17: 30$ & 279 & 263 & 16 & 331 & $4.85 \%$ & $\mathrm{c}$ \\
\hline $8: 19: 30$ & 290 & 263 & 27 & 306 & $8.84 \%$ & $\mathrm{c}$ \\
\hline $8: 21: 30$ & 290 & 263 & 28 & 317 & $8.69 \%$ & $\mathrm{c}$ \\
\hline $8: 23: 30$ & 234 & 263 & 0 & 262 & $0.00 \%$ & $\mathrm{~d}$ \\
\hline $8: 25: 30$ & 271 & 263 & 8 & 271 & $2.88 \%$ & $\mathrm{c}$ \\
\hline $8: 27: 30$ & 274 & 263 & 12 & 282 & $4.13 \%$ & $\mathrm{c}$ \\
\hline $8: 29: 30$ & 273 & 263 & 10 & 284 & $3.52 \%$ & $\mathrm{c}$ \\
\hline
\end{tabular}

“--” indicates no congestion warning level. 


\section{(iii) Transfer Efficiency}

The length of the transfer channel is $160 \mathrm{~m}$. The theoretical walking velocity is set to $1.5 \mathrm{~m} / \mathrm{s}$, and the passing time is $107 s$. When considering the distance connecting with the platform, the total theoretical transfer time is $152 \mathrm{~s}$. Transfer efficiency $\eta_{t}$ can be calculated by Eq. 8 .

Some cameras were installed in the entrance and exit of the transfer channel, and the average transfer time was calculated every six minute. From the Eq. 8 results, the transfer efficiency is shown in (Table 7).

As we can see from Table 7, during the morning peak hour, all the passengers can transfer from Line 1 to Line 10. Mostly, the congestion warning level fluctuated between Level 3 and Level 4. After 8:00, the congestion reached a stable degree, and the passengers could walk freely.

Table 7. Congestion warning level for the transfer channel in GuoMao station.

\begin{tabular}{|c|c|c|c|}
\hline time & Transfer time/second & Transfer efficiency $\boldsymbol{\eta}_{\boldsymbol{t}}$ & Congestion warning level \\
\hline $07: 31: 30$ & 246 & 1.62 & 3 \\
\hline $07: 37: 30$ & 220 & 1.45 & 3 \\
\hline $07: 43: 30$ & 195 & 1.28 & 4 \\
\hline $07: 49: 30$ & 235 & 1.67 & 3 \\
\hline $07: 55: 30$ & 254 & 1.22 & 3 \\
\hline $08: 01: 30$ & 186 & 1.47 & 3 \\
\hline $08: 07: 30$ & 224 & 1.61 & 3 \\
\hline $08: 13: 30$ & 244 & 1.26 & 3 \\
\hline $08: 19: 30$ & 192 & 1.21 & \\
\hline $08: 25: 30$ & 184 & & \\
\hline
\end{tabular}

\subsection{Congestion Warning Level}

According to the descriptions, data and Table 5, the congestion warning level of GuoMao Station in morning peak hour can be seen in (Table 8 ).

Table 8. Warning level of GuoMao station in morning peak hour.

\begin{tabular}{|c|c|c|c|}
\hline Time & $\boldsymbol{\eta}_{\boldsymbol{t}}$ & $\boldsymbol{\eta}_{\boldsymbol{r}}$ & congestion warning level for station \\
\hline $07: 31: 30$ & 3 & - & IV \\
\hline $07: 37: 30$ & 3 & $\mathrm{~d}$ & IV \\
\hline $07: 43: 30$ & 4 & $\mathrm{c}$ & III \\
\hline $07: 49: 30$ & 3 & $\mathrm{~b}$ & III \\
\hline $07: 55: 30$ & 3 & $\mathrm{c}$ & III \\
\hline $08: 01: 30$ & 4 & $\mathrm{c}$ & IV \\
\hline $08: 07: 30$ & 3 & $\mathrm{c}$ & III \\
\hline $08: 13: 30$ & 3 & $\mathrm{~b}$ & III \\
\hline $08: 19: 30$ & 4 & $\mathrm{c}$ & IV \\
\hline $08: 25: 30$ & 4 & $\mathrm{c}$ & IV \\
\hline
\end{tabular}

“--” indicates no congestion warning level.

Generally, the operation performance is good during the morning peak hour. After the peak hour, the congestion is substantially reduced.

\subsection{Congestion Precaution Response}

During the morning peak-hour, the condition of the GuoMao station is mostly orderly. But several measures can be taken to improve the safety and circulation of the passengers. First, some zigzag fences can be put in the transfer channel to avoid passenger-path conflicts. Because of the unbalanced transfer volume in opposite directions, the operators can adjust the width of the channel and occupy some space of the transfer channel from Line 10 to Line 1 . In this way the efficiency of the transfer channel might be substantially improved.

On the platform, the passengers should be directed to the specific stairs, which are at the two ends of the platform, to increase the efficiency of the exit. 
Also, if the volume of the passengers approaches the limit of the station, the checking-in passengers can be limited. And up stations, such as Jian Guomen station, need to cooperate with GuoMao station to reduce their loading rate. This will let more passengers board on the trains, and thereby reduce the platform retention rate.

\section{CONCLUSION}

The aim of this research is to increase the understanding of the concept of congestion evaluation and precaution. And an example of application of congestion precaution theory and methods in a metro station is presented. The main contributions of this study:

(1) We proposed three indexes to reflect the actual operation condition of the metro station. For each of the different indexes, the calculation formula and the threshold for each warning level were given.

(2) From Fig. (2) to Table 5, a new methodology for different warning levels is established, which is much easier to handle and more workable in real situation.

(3) Based on the determination of an appropriate congestion warning level, different response actions are respectively suggested.

(4) The practical application indicated the feasibility and practicability of the congestion precaution methodology presented. The model resumes less than one second evaluating the congestion condition in the station, which illustrates the efficiency of the model to a certain extent.

Although the congestion precaution theory was successfully proven, some possible enhancements need further research:

(1) This study focused only on the congestion precaution methodology as applied to one metro station. Beijing metro is a large system containing many stations and sections. Congestion evaluation and precaution theory needs to include all of them.

(2) This study mainly discussed the warning indexes and warning levels. The response time and the advanced information mentioning time also need future study.

\section{CONFLICT OF INTEREST}

The authors declare that there is no conflict of interest regarding the publication of this paper.

\section{ACKNOWLEDGEMENTS}

This paper was supported by National Natural science Foundation of China (U1434207), by the Fundamental Research funds for the central Universities (2014JBM337,2015JBM046), by Beijing Natural Science Foundation (9132015) and by projects in the National Science \& Technology Pillar Program (NO.2011BAG01G01). The authors would thank the editor of the journal and the anonymous reviewers, for their constructive suggestions and comments that have led to a significant improvement of this paper.

\section{REFERENCES}

[1] H.H. Einstein, and R. Sousa, "Warning systems for natural threats", Assess. Manage. Riskfor Eng. Syst. Geohazards, vol. 1, pp. 3-20, 2007.

[2] D.W. Li, Y.X. Sun, and J.L. Huang, "Study on early warning of passenger flows on mass transit railway", Urban Rapid Rail Transit, vol. 26, pp. 62-66, 2013.

[3] E.I. Vlahogianni, J.C. Golia, and M.G. Karlaftis, "Short-term traffic forecasting: Overview of objectives and methods", Transp. Rev., vol. 24, pp. 533-557, 2004.

[http://dx.doi.org/10.1080/0144164042000195072]

[4] C.K. Moorthy, and B.G. Ratcliffe, "Short term traffic forecasting using time series methods", Trans. Plan. Technol., vol. 12, pp. 45-56, 1988. [http://dx.doi.org/10.1080/03081068808717359]

[5] J. Guo, W. Huang, and B.M. Williams, "Adaptive Kalman filter approach for stochastic short-term traffic flow rate prediction and uncertainty quantification", Transp. Res., Part C Emerg. Technol., vol. 43, pp. 50-64, 2014. [http://dx.doi.org/10.1016/j.trc.2014.02.006]

[6] J.R. Stroud, M.L. Stein, B.M. Lesht, D.J. Schwab, and D. Beletsky, "An ensemble Kalman filter and smoother for satellite data assimilation", J. Am. Stat. Assoc., vol. 105, pp. 978-990, 2010.

[http://dx.doi.org/10.1198/jasa.2010.ap07636] 
[7] Y.C. Xie, and Y.L. Zhang, "A wavelet network model for short-term traffic volume forecasting", J. Intell. Trans. Syst., vol. 10, pp. 141-150, 2006.

[http://dx.doi.org/10.1080/15472450600798551]

[8] T.L. Sellnow, M.W. Seeger, and R.R. Ulmer, "Chaos theory, informational needs, and natural disasters", J. Appl. Commun. Res., vol. 30, pp. 269-292, 2002.

[http://dx.doi.org/10.1080/00909880216599]

[9] G. Huisken, "Soft-computing techniques applied to short-term traffic flow forecasting", Syst. Anal. Model. Sim., vol. 43, pp. 165-173, 2003.

[10] K. Kumar, M. Parida, and V.K. Katiyar, "Short term traffic flow prediction in heterogeneous condition using artificial neural network", Transport, vol. 28, pp. 1-9, 2013.

[11] B. Abdulhai, H. Porwal, and W. Recker, "Short-term traffic flow prediction using neuro-genetic algorithms", J. Intell. Trans. Syst., vol. 7, pp. 3-41, 2002.

[http://dx.doi.org/10.1080/713930748]

[12] Y. Sun, M.X. Lang, D.Z. Wang, and L.Y. Liu, "A PSO-GRNN model for railway freight volume prediction: Empirical study from China", J. Ind. Eng. Manag., vol. 7, pp. 413-433, 2014. [http://dx.doi.org/10.3926/jiem.1007]

[13] Y. Wei, and M.C. Chen, "Forecasting the short-term metro passenger flow with empirical mode decomposition and neural networks", Transp. Res., Part C Emerg. Technol., vol. 21, pp. 148-162, 2012. [http://dx.doi.org/10.1016/j.trc.2011.06.009]

[14] A.K. Fard, and M.R. Akbari-Zadeh, "A hybrid method based on wavelet, ANN and ARIMA model for short-term load forecasting", J. Exp. Theor. Artif. Intell., vol. 26, pp. 167-182, 2014. [http://dx.doi.org/10.1080/0952813X.2013.813976]

[15] A. Polus, J.L. Schofer, and A. Ushpiz, "Pedestrian flow and level of service", J. Transp. Eng., vol. 109, pp. 46-56, 2010. [http://dx.doi.org/10.1061/(ASCE)0733-947X(1983)109:1(46)]

[16] J.N. Lu, F. Zheng, Z.M. Lu, and C.M. Zhao, "Mathematical model of evacuation speed for personnel in buildings", Eng J. Wuhan Univ., vol. 35 , pp. 66-70, 2002.

[17] G.G. Løvås, "Modeling and simulation of pedestrian traffic flow", Transp. Res., Part B: Methodol., vol. 28, pp. 429-443, 1994. [http://dx.doi.org/10.1016/0191-2615(94)90013-2]

[18] K. Anko, H. Ota, and T. Oki, "Forecasting the Flow of People", Railway Res. Rev., vol. 45, pp. 8-14, 1988.

[19] F.S. Tian, H.X. Lv, and H.Z. Li, "The design of metro train routing based on optimized train set configuration", Railway Trans. Econ., vol. 28, pp. 26-28, 2006.

[20] L. Zhang, and F.K. Chen, "On large passenger flow operating organizations at metro station", Railway Urban Mass Transit, vol. 24, pp. 47-90, 2011.

[21] J.R. Wu, J.D. Feng, and J.H. Ye, "Capacity analysis of magnetic card and contactless IC card automatic fare gate in railway stations", J. Tongji Univ., vol. 21, pp. 85-91, 2010.

Received: July 13, 2015

Revised: August 17, 2015

Accepted: September 7, 2015

(C) Lu and Han; Licensee Bentham Open.

This is an open access article licensed under the terms of the Creative Commons Attribution-Non-Commercial 4.0 International Public License (CC BY-NC 4.0) (https://creativecommons.org/licenses/by-nc/4.0/legalcode), which permits unrestricted, non-commercial use, distribution and reproduction in any medium, provided the work is properly cited. 